\title{
APLIKASI INTERAKTIF TAHFIDZ AL-QURAN JUZ AMMA (STUDI KASUS DI SDI MOHAMMAD HATTA)
}

\author{
Rahmat Solihin \\ STAI Asy-Syukriyyah Tangerang \\ Email:solihin.elrahmat@gmail.com \\ Orcid Id: 0000-0001-7517-3051
}

\begin{abstract}
Tahfidz Al-Quran really needs to be taught at all levels of education, especially on early age as in the level of elementary school. Apart from the fact that the AlQuran is a guidelife for all mankind, it is also because by memorizing the AlQuran, students' intelligence and academic achievement can be improved. This study aims to find out how the implementation of the interactive application tahfidz juz amma in improving the student's memorization quality of SDI Mohammad Hatta Malang. The method used in this study is a quantitative method with a total of 12 research subjects who are learning groups in Al-Quran learning which consists of V grade and VI grade students of SDI Mohammad Hatta Malang. The instruments of data collection used were learning test result, questionnaires, interviews and observation. Based on the results of the study, it is known the value of the $t_{\text {count }}=3.450$ and the value of $t_{\text {table }}=2.201$, this shows that 3,450 $>2,201$. From this result it can be seen that the value of $t_{\text {count }}$ is greater than the value of $t$ table, so it can be concluded in general that the interactive application of tahfidz juz amma is effective to help improving the quality of students memorization in tahfidz Al-Quran juz amma. While the attractiveness level of the application is at a very attractive level with an attractiveness level of $80 \%$.
\end{abstract}

Keywords:Interactive Application; Tahfidz Al-Quran;Juz Amma

\begin{abstract}
Abstrak
Tahfidz Al-Quran sangat penting untuk diajarkan di semua jenjang pendidikan, terlebih lagi sejak usia dini seperti pada sekolah dasar. Selain karena Al-Quran adalah pedoman bagi seluruh umat manusia, juga karena dengan menghafal AlQuran, kecerdasan dan prestasi akademik siswa dapat ditingkatkan. Penelitian ini bertujuan untuk mengetahui bagaimana penerapan aplikasi interaktif tahfidz juz amma dalam meningkatkan kualitas hafalan siswa SDI Mohammad Hatta Malang. Metode yang digunakan dalam penelitian ini adalah metode kuantitatif dengan subjek penelitian berjumlah 12 orang yang merupakan kelompok belajar dalam pembelajaran Al-Quran dan terdiri dari siswa kelas V dan siswa kelas VI SDI Mohammad Hatta Malang. Instrumen pengumpulan data yang digunakan adalah hasil tes belajar, angket, wawancara dan observasi. Berdasarkan hasil penelitian, diketahui bahwa nilai $t_{\text {hitung }}=3,450$ dan nilai $t_{\text {tabel }}=2,201$, hal ini menunjukkan
\end{abstract}


bahwa 3,450> 2,201. Dari hasil ini dapat diketahui bahwa nilai $t_{\text {hitung }}$ lebih besar dari nilai $t_{\text {tabel, }}$ sehingga dapat disimpulkan secara umum bahwa aplikasi interaktif tahfidz juz amma efektif untuk membantu meningkatkan kualitas hafalan siswa dalam pembelajaran tahfidz Al-Quran juz amma. Sedangkan tingkat kemenarikan aplikasi berada pada tingkat yang sangat menarik dengan tingkat kemenarikan $80 \%$.

Keywords:aplikasi interaktif; tahfidz Al-Quran; juz amma

\section{A. PENDAHULUAN}

Al-Quran pada masa Nabi Muhammad dipelihara dengan dua cara, yaitu dengan tulisan dan hafalan(Khalid, 2011). Menghafal Al-Quran merupakan salah satu metode yang sangat tepat untuk menjaga keaslian Al-Quran sejak diwahyukan hingga sekarang, bahkan masa yang akan datang. Untuk itu, hafalan Al-Quran atau tahfidz Al-Quran sangat perlu diajarkan pada semua jenjang pendidikan. Bahkan membaca atau mendengarkan bacaan Al-Quran dengan hikmat niscaya akan mendapat petunjuk dari Allah SWT (Dawud Al-Aththar, 1994). Sehingga tidaklah salah jika pembelajaran Al-Quran merupakan salah satu pembelajaran yang penting dan dimasukkan ke dalam kurikulum pendidikan, bahkan sejak pendidikan dasar sekalipun.

Problematika yang terjadi dalam pembelajaran tahfidz Al-Quran sebagaimana yang peneliti temukan, diantaranya yaitu kurangnya perhatian terhadap kualitas hafalan siswa. guru lebih berfokus pada target hafalan (kuantitas) dari pada menjaga kualitas hafalan siswa. Selain itu, diantara tuntutan kurikulum adalah mengajarkan hafalan Al-Quran kepada siswa sebagai bagian dari mata pelajaran PAI bahkansejak siswa berada di kelas rendah(Solihin, 2020). Tentu saja hal ini menyebabkan banyak diantara siswa yang belum mampu membaca Al-Quran namun sudah dibebankan untuk menghafal, dan hal ini berpengaruh terhadap kualitas hafalan mereka.

Berdasarkan hasil observasi dan wawancara pada Sekolah Dasar Islam Mohammad Hatta Kota Malang (selanjutnya disebut SDI Mohammad Hatta) diketahui bahwa penggunaan media dalam pembelajaran tahfidz Al-Quran masih sangat minim. Hal ini akhirnya berdampak pada bacaan siswa menjadi kurang diperhatikan karena sangat bergantung pada bacaan yang diperdengarkan oleh guru, padahal tidak semua guru yang mengajar di SDI Mohammad Hatta memiliki bacaan yang fasih. Data menunjukkan bahwa rata-rata lulusan SDI Mohammad Hatta, mampu menghafalkan juz amma, namun belum semua yang mampu mencapai kriteria bacaan yang fasih.

Problematika ini tidak hanya terjadi pada SDI Mohammad Hatta, di beberapa beberapa tempat lain juga terjadi hal demikian. Berdasarkan temuan 
Disdik Singkawang yang melakukan tes mengaji dan tulisan Arab untuk guru Agama Islam tingkat SD dan Madrasah Ibtidaiyah se-Kota Singkawang pada Kamis, 9 September 2014. Hasilnya, dari 107 guru hanya 22 orang yang fasih dan membaca sesuai kaidah tajwid("Guru Agama Islam Di Singkawang Kurang Pandai Mengaji," 2014). Begitu pula hasil diklat bagi guru PAI di Pemekasan, ditemukan data bahwa 60 guru PAI yang mengikuti diklat tersebut, rata-rata tidak fasih membaca Al Qur'an yang sesuai dengan Peraturan Perda Nomor 4 tahun 2014 tentang Baca-Tulis Al Qur'an(“Banyak Guru Pamekasan Belum Fasih Baca Al-Quran," 2016). Dengan tidak adanya alat bantu mengajar berupa media pembelajaran, maka dikhawatirkan akan berdampak pula pada bacaan siswa yang menjadi kurang fasih karena tidak ada pemodelan yang benar-benar tepat.

Penggunaan media yang tepat dalam pembelajaran akan sangat membantu dalam meminimalisir problematika ini. Menurut Sanaky, manfaat media pada proses pembelajaran adalah agar perhatian siswa yang kurang terfokus akan menjadi lebih antusias pada pelajaran(Sanaky, 2011). Terlebih dalam tahfidz AlQuran, siswa yang masih berada pada kelas rendah masih belum bisa membaca Al-Quran. Oleh karena itu, cara mereka menghafal adalah dengan mendengarkan bacaan dari pengajarnya, sehingga peran pengajar akan sangat dominan dalam pembelajaran. Jika pengajar kurang fasih bacaannya, ataupun tidak bisa membuat siswa fokus dalam menghafal, maka hal ini akan berdampak buruk bagi keberhasilan pembelajaran tahfidz Al-Quran pada SDI Mohammad Hatta.

Terlepas dari problematika yang telah dijabarkan, pembelajaran tahfidz Al-Quran yang dikembangkan oleh SDI Mohammad Hatta menjadi salah satu program andalan sekolah yang memiliki banyak manfaat, tidak hanya bagi sekolah, terlebih lagi utamanya bagi siswa sendiri. Bagi sekolah, manfaat pembelajaran tahfidz Al-Quran diantaranya yaitu: akan menunjang tercapainya tujuan sekolah; mewujudkan lulusan yang hafizh dan hafizhah (penghafal AlQuran); menciptakan lingkungan sekolah yang dekat dengan Al-Quran; dan program ini menjadi nilai jual tersendiri pada masyarakat umum.Sedangkan manfaat bagi siswa sendiri yaitu: meningkatkan intelejensi(Shirvani et al., 2015); dan meningkatkan prestasi akademik siswa(Al Hafiz et al., 2016; Jahangir \& Nawaz, 2014; Nawaz \& Jahangir, 2015).

Terdapat banyak penelitian mengenai media pembelajaran berbentuk media interaktif(Budiman \& Ariani, 2014; Faroqi \& Maula, 2014; Novaliendry, 2013; Shalikhah, 2016). Dalam hal ini, peneliti menentukan media pembelajaran yang diteliti adalah aplikasi interaktif tahfidz juz amma yang telah peneliti kembangkan sebelumnya. Sehingga dengan penggunaan aplikasi interakif ini akan diketahui bagaimana peningkatan kualitas hafalan siswa pada subjek penelitian yang ditentukan. 
Berdasarkan latar belakang yang telah dijelaskan maka peneliti menentukan tujuandalam penelitian ini yaitu untuk mengetahui bagaimana implementasi aplikasi interaktif tahfidz juz amma dalam meningkatkan kualitas hafalan siswa SDI Mohammad Hatta Malang.

\section{B. METODOLOGI}

Jenis penelitian yangdigunakan dalam penelitian ini adalahpenelitian lapangan (field research) dengan menggunakan metode penelitian kuantitatif. Meskipun penelitian ini merupakan penelitian kuantitatif, tetapi tidak menutup kemungkinan adanya pemaparan data secara deskriptif untuk lebih memperdalam pembahasan. Subjek dalam penelitian ini yaitu siswa SDI Mohammad Hatta Kota Malang yang berjumlah 12 orang.Mereka adalah kelompok belajar dalam pembelajaran Al-Quran yang terdiri dari siswa kelas V dan kelas VI. Instrumen pengumpulan data yang digunakan yaitu tes hasil belajar, angket,wawancara, dan observasi.

\section{HASIL DAN PEMBAHASAN}

\section{Desain Aplikasi Interaktif Tahfidz Juz Amma}

Aplikasi interaktif tahfidz juz amma yang diujicobakan berupa perangkat lunak (software) yang berisi teks, gambar, suara, animasi dan video yang dikemas menjadi dua versi, yaitu versi windows dan versi android. Aplikasi versi windows dikemas dalam bentuk Compact Disc (CD) pembelajaran yang dapat dioperasikan dengan seperangkat komputer atau laptop,sedangkan aplikasi interaktif versi android dikemas menjadi aplication installeryang dapat diinstal dan dioperasikan dengan smartphone android. Media dikemas dalam bentuk aplikasi interaktif agar siswa yang dominan menggunakan gadget(Holilulloh \& Youssef, 2020) bisa menggunakan waktu mereka dengan aplikasi yang bermanfaat.

Aplikasi interaktif ini juga didesain untuk pembelajaran tahfidz secara klasikal maupun individual, sehingga aplikasi tidak hanya bisa digunakan di ruang kelas, tetapi juga bisa digunakan secara mandiri oleh siswa. Terlebih lagi ketika siswa di rumah, pemanfaatan teknologi dalam pembelajaran akan sangat membantu dalam pembelajaran siswa secara mandiri. Tentunya, peran orang tua dalam mengontrol kegiatan siswa di rumah juga sangat diperlukan (Purnama, 2019).

Tampilan aplikasi interaktif tahfidz juz amma ini didesain sedemikian rupa agar menarik untuk digunakan siswa yang merupakan anak usia 6-12 tahun. Penggunanan warna yang cerah dan disertai animasi dan ilustrasi dapat 


\section{dan Manajemen Pendidikan Dasar}

Homepage: https://ejournal.stainupwr.ac.id/

Email: sibyan.stainupwrj@gmail.com

E-ISSN: : 2599-2732

meningkatkan taraf kemenarikan aplikasi. Tampilan aplikasi interaktif yang diuji coba pada responden dapat terlihat dari gambar 1 dan gambar 2 berikut.

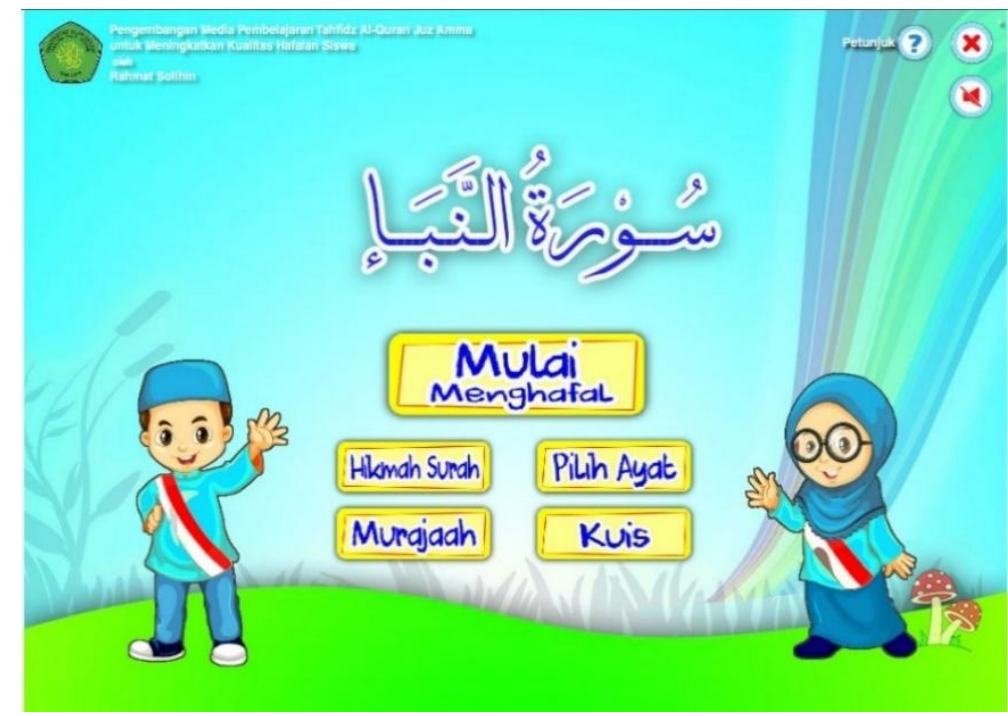

Gambar 1. Halaman Depan

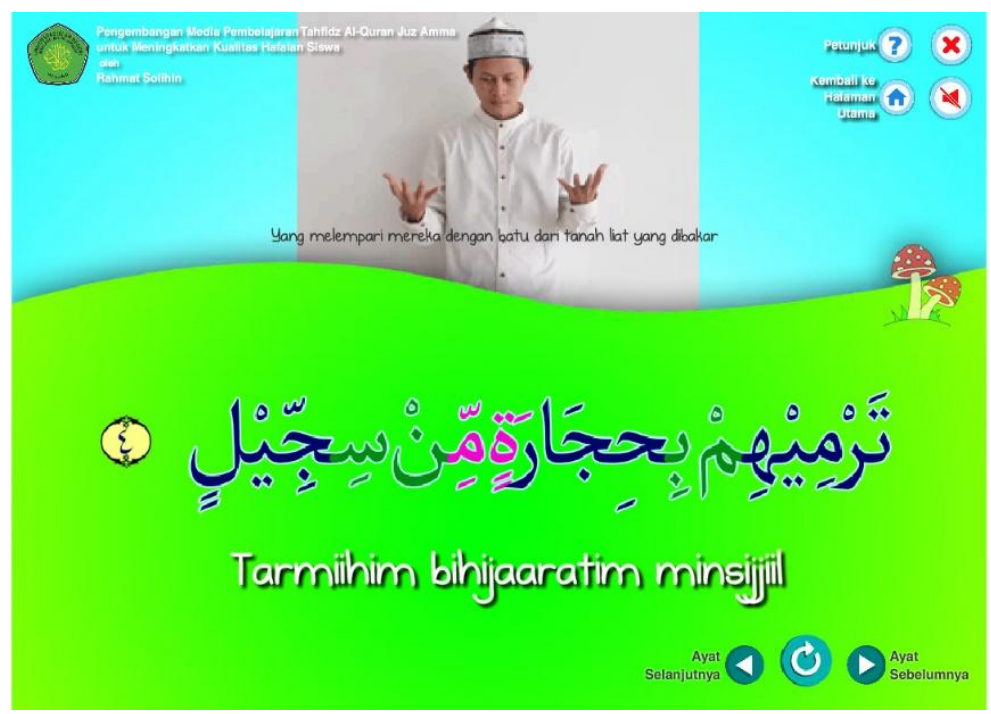

Gambar 2. Halaman Menghafal

Aplikasi interaktif tahfidz juz amma yang diujicobakan pada responden memuat 37 surah yang terdapat dalam juz Amma yang merupakan juz ke-30 dalam Al-Quran. Audio yang digunakan merupakan bacaan Al-Quran dengan Lagu Hijaz tiga nada. Dilengkapi dengan visual berupa bacaan teks Al-Quran yang sesuai dengan audio yang dibaca serta video yang memperagakan gerakan yang disesuaikan dengan makna bacaan. Gerakan dalam aplikasi ini tentunya akan 
lebih efektif jika dilakukan bersama-sama antara guru dan siswa, karena dengan penggunaan kinestetik dalam menghafal, akan dapat membantu memperkuat hafalan siswa (DePorter, 2005).

\section{Uji Efektivitas Aplikasi Interaktif Tahfidz Juz Amma}

Uji coba di lapangan dilakukan sebanyak tiga kali pertemuan pada jam mata pelajaran Al-Quran yang dilaksanakan setiap hari pada jam 07.00 sampai 08.10. Uji coba dilakukan bertujuan untuk mengetahui keefektifan aplikasi yang diujicoba dengan mengukur peningkatan nilai pre-test dan post-test siswa.

Surah yang dipilih untuk diujicobakan adalah Surah Adh-Dhuhaa dan Surah Al-Insyirah. Dua surah ini dipilih karena berada pada tengah-tengah juz amma, dan jumlah ayatnya tidak terlalu banyak dan tidak terlalu sedikit. Selain itu, kedua surah ini sering didengar oleh siswa dan sudah pernah diajarkan oleh guru dengan menggunakan media sebelumnya, yaitu peraga bacaan dan papan tulis.

Analisis data untuk keefektifan aplikasi pembelajaran tahfidz Al-Quran juz amma dapat dilihat dari tes terhadap siswa.Peneliti menggunakan tes tulis berupa soal pilihan dan tes lisan berupa uji hafalan surah. Analisis tes tersebut menggunakan tes awal dan tes akhir dalam rangka untuk mengetahui data kemampuan awal (pretest) dan data kemampuan akhir (posttest). Data nilai yang diperoleh dapat dilihat pada tabel 1 berikut.

Tabel 1. Nilai Pre-test dan Post-test Responden

\begin{tabular}{|l|l|r|r|}
\hline \multirow{2}{*}{ o } & \multirow{2}{*}{ Responden } & \multicolumn{2}{|c|}{ Nilai } \\
\cline { 3 - 4 } & Responden 1 & Pre-test & Post-test \\
\hline & Responden 2 & 93,6 & 96,8 \\
\hline & Responden 3 & 95,2 & 98,4 \\
\hline & Responden 4 & 96,4 & 96,8 \\
\hline & Responden 5 & 81,4 & 98,6 \\
\hline & Responden 6 & 95,3 & 83,4 \\
\hline & Responden 7 & 86,8 & 96,8 \\
\hline & Responden 8 & 82,2 & 93,6 \\
\hline & Responden 9 & 93,6 & 92,2 \\
\hline \multirow{2}{*}{0} & Responden 10 & 87,9 & 93,6 \\
\hline \multirow{2}{*}{1} & Responden 11 & 81,4 & 86 \\
\hline \multirow{2}{*}{2} & & 92,4 & \multirow{2}{*}{98,4} \\
\hline
\end{tabular}


Konversi data tabel 1 menjadi grafik dapat dilihat pada gambar 3 berikut.

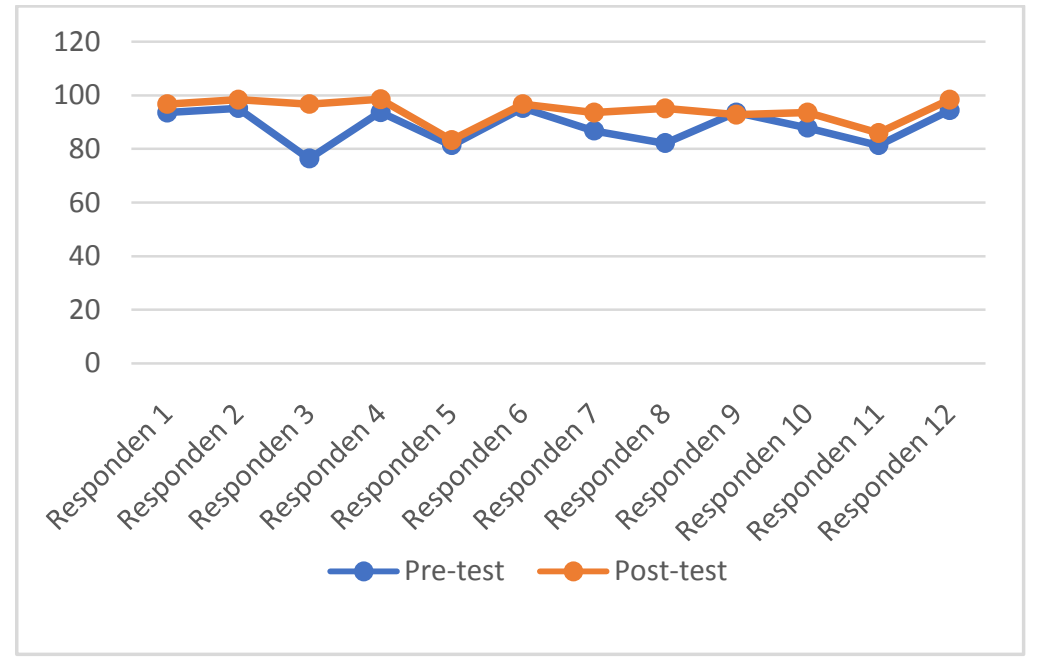

Gambar 3. Grafik Nilai Pre-Test dan Post-Test Siswa

Data ini kemudian dianalisis dengan menggunakan uji-t untuk mengetahui signifikansi perbedaan antara pembelajaran yang menggunakan media terdahulu dengan pembelajaran menggunakan media yang telah dikembangkan yaitu aplikasi interaktif tahfidz juz amma. Analisis uji-t pada nilai pre-test dan post-test dihitung menggunakan aplikasi SPSS 16 (Paired Samples Test) yang dapat dilihat pada tabel berikut.

Tabel 2. Hasil Uji-t Menggunakan SPSS 16

\begin{tabular}{|c|c|c|c|c|c|c|c|c|}
\hline & \multicolumn{5}{|c|}{ Paired Differences } & \multirow[b]{3}{*}{$\mathrm{t}$} & \multirow{3}{*}{\multicolumn{2}{|c|}{$\begin{array}{l}\text { Sig. } \\
\text { f tailed })\end{array}$}} \\
\hline & \multirow[b]{2}{*}{ Mean } & \multirow{2}{*}{$\begin{array}{l}\text { Std. } \\
\text { Deviation }\end{array}$} & \multirow{2}{*}{$\begin{array}{ll}\text { Std. } & \text { Error } \\
\text { Mean } & \end{array}$} & \multicolumn{2}{|c|}{\begin{tabular}{|c|}
$95 \%$ \\
Interval of the Difference
\end{tabular}} & & & \\
\hline & & & & Lower & Upper & & & \\
\hline $\begin{array}{l}\text { Ppretest } \\
\text { postest }\end{array}$ & $\begin{array}{l}- \\
5.7083\end{array}$ & 5.7320 & 1.6547 & -9.3502 & -2.0664 & $\begin{array}{l}- \\
3.450\end{array}$ & 1 & .003 \\
\hline
\end{tabular}

Berdasarkan data tersebut, diketahui nilai $\mathrm{t}_{\text {hitung }}$ adalah $-3,450$ dan baris sig (2-tailed) menunjukkan nilai probabilitas 0,003. Kemudian nilai $t$ hitung dikonsultasikan dengan nilai $\mathrm{t}_{\text {tabel }}$ pada $\alpha=0,05$ dan $\mathrm{df} 11$, maka diperoleh $\mathrm{t}_{\text {tabel }}=$ 2,201 dan hal ini menunjukkan 3,450 > 2,201. Terlihat bahwa nilai $\mathrm{t}$ hitung lebih besar daripada nilai $\mathrm{t}$ tabel, artinya $\mathrm{H}_{1}$ diterima dan $\mathrm{H}_{0}$ ditolak. Jadi, dapat disimpulkan bahwa terdapat perbedaan kualitas hafalan yang signifikan antara sebelum menggunakan aplikasi dan sesudah menggunakan aplikasi yang diujicoba.

Perbedaan kualitas hafalan siswa sebelum dan sesudah menggunakanaplikasi interaktif tahfidz juz amma terlihat dari peningkatan tiga 
kaidah kualitas hafalanyaitu kekuatan hafalan, kefashihan bacaan dan pemahaman terhadap surah yang dihafalkan(Baduwalin, 2016). Peningkatan ini salah satunya didasari pada penggunaan audio, visual, dan kinestetik dalam aplikasi.

Aspek pertama yang terjadi peningkatan adalah aspek kekuatan hafalan siswa yang semakin lancar dalam bacaannya ketika menghafal. Berbeda ketika aplikasi belum diujicobakan, bacaan siswa masih tersendat dan kadang masih ada ayat yang tertukar. Bahkan, setelah menggunakan aplikasi ini, ketika dicoba menyambung ayat sekalipun siswa masih bisa melafalkan hafalannya dengan benar. Inilah salah satu kelebihan dari aplikasi yang diimplementasikan kepada siswa yaitu mengakomodasi tiga gaya belajar siswa, sehingga lebih meningkatkan kekuatan hafalan mereka(DePorter, 2005).

Aspek berikutnya yaitu mengenai kefashihan bacaan. Sesudah menggunakan aplikasi, bacaan siswa menjadi lebih baik terutama pada aspek tajwidnya. Ketika sebelum menggunakan aplikasi, banyak bacaan dengung dan qalqalah yang terlewat oleh siswa. Namun, ketika sudah ditekankan pada saat penggunaan aplikasi dalam pembelajaran menggunakan nada lagu hijaz(Macmillan, 2004)dan langkah-langkah pembelajaran wafa(WafaIndonesia, 2015), serta adanya tajwid warna dalam aplikasi, siswa menjadi lebih berhati-hati dalam melafalkan hafalan mereka. Hal ini akhirnya berdampak pada kefashihan bacaan siswa yang lebih baik dari sebelumnya.

Aspek ketiga dalam peningkatan kualitas hafalan yaitu pemahaman terhadap surah yang mereka hafalkan. Siswa juga mengetahui lebih banyak terhadap surah yang mereka hafalkan sesudah uji coba aplikasi, yaitu berkaitan dengan arti dan hikmah surah. Sebelumnya, mereka sama sekali belum mengetahui arti dan hikmah surah tersebut. Meskipun jawaban mereka benar pada saat pre-test, sebagian besar adalah hasil spekulasi dan pemahaman-pemahaman mereka yang telah mereka pelajari sebelumnya. Hal ini terlihat pada saat uji coba aplikasi, siswa terlihat begitu apresiatif terhadap materi yang terdapat dalam aplikasi. Dengan bantuan ilustrasi yang ada pada aplikasi, siswa menjadi lebih bersemangat dan lebih cepat dalam mengingat hikmah surah yang mereka hafalkan (Sanaky, 2009; Sumantri \& Permana, 2001). Tentunya hal ini juga tidak terlepas dari pengaruh guru dalam mengajar. Guru yang menggunakan aplikasi, berperan aktif dalam memotivasi siswa serta menjelaskan materi yang tersedia. Hal ini sesuai dengan kriteria pemilihan media yang baik dimana media yang digunakan harus mampu menyesuaikan dengan hasil yang ingin dicapai, sesuai dengan kelompok sasaran, dan guru dapat mengoperasikannya dengan mudah(Arsyad, 2007). 


\section{Aspek Kemenarikan Aplikasi Interaktif Tahfidz Juz Amma}

Data kemenarikan diperoleh dari angket yang diberikan kepada siswa dalam menggunakan aplikasi yang diujicoba. Rekapitulasi jawaban siswa dalam hasil uji kemenarikan aplikasi, dapat dilihat pada tabel berikut.

Tabel 3. Hasil Uji Kemenarikan Produk

\begin{tabular}{|l|l|l|}
\hline Responden & $\begin{array}{l}\text { Jumlah } \\
\text { Skor } \\
\text { Perolehan }\end{array}$ & $\begin{array}{l}\text { Jumlah } \\
\text { Skor } \\
\text { Maksimal }\end{array}$ \\
\hline Responden 1 & 29 & 40 \\
\hline Responden 2 & 38 & 40 \\
\hline Responden 3 & 36 & 40 \\
\hline Responden 4 & 34 & 40 \\
\hline Responden 5 & 33 & 40 \\
\hline Responden 6 & 28 & 40 \\
\hline Responden 7 & 29 & 40 \\
\hline Responden 8 & 33 & 40 \\
\hline Responden 9 & 34 & 40 \\
\hline Responden 10 & 31 & 40 \\
\hline Responden 11 & 22 & 40 \\
\hline Responden 12 & 37 & 40 \\
\hline Jumlah skor & 384 & 480 \\
\hline
\end{tabular}

Data pada tabel 3 tersebut kemudian dihitung untuk mendapatkan angka tingkat kemenarikan produk sebagai berikut.

$\mathrm{M}=\frac{\sum(\text { skor perole han })}{\sum(\text { skor maksimal })} \times 100 \%$

$\mathrm{M}=\frac{\sum 384}{\sum 480} \times 100 \%$

$\mathrm{M}=80 \%$

Hasil perhitungan tersebut dicocokkan dengan kriteria yang sudah ditentukan. Berdasarkan data yang diperoleh yaitu sebesar $80 \%$ dan kemudian dikonversikan dengan kriteria kemenarikan produk maka aplikasi dapat dikatakan sangat menarik.

\section{KESIMPULAN}

Berdasarkan hasil penelitian yang telah diuraikan, diketahui nilai $\mathrm{t}$ hitung adalah $-3,450$ dan nilai $t$ tabel $=2,201$, hal ini menunjukkan 3,450 $>2,201$. Dari data ini terlihat bahwa nilai $t_{\text {hitung }}$ lebih besar daripada nilai $t_{\text {tabel }}$, sehingga dapat 
disimpulkan secara umum bahwa aplikasi interaktif tahfidz juz amma ini efektif untuk membantu meningkatkan kualitas hafalan siswa dalam pembelajaran tahfidz Al-Quran juz amma. Kualitas hafalan yang diuji mencakup tiga aspek yaitu kekuatan hafalan, kefashihan bacaan dan pemahaman terhadap surah yang dihafalkan. Berikutnya pada tingkat kemenarikan aplikasi setelah diujicoba pada responden yang berjumlah 12 orang, berada pada kategori sangat menarik dengan nilai kemenarikan $80 \%$, sehingga dapat diketahui bahwa aplikasi interaktif tahfidz juz amma ini memiliki tingkat kemenarikan yang tinggi.

\section{DAFTAR PUSTAKA}

Al Hafiz, M. M., Yusof, M. F., Ghazali, M. A., \& Md. Sawari, S. S. (2016). Descriptive Qualitative Teaching Method of Memorization in The Institution of Tahfiz Al-Quran Wal Qiraat Pulai Condong and the Students' Level of Academic Excellence. Mediterranean Journal of Social Sciences, 7(1), 7985. https://doi.org/10.5901/mjss.2016.v7n1s1p79

Arsyad, A. (2007). Media Pembelajaran. RajaGrafindo Persada.

Baduwalin, A. B. S. (2016). Asraru Hifzhi Al-Quranil Karim. Aqwam.

Banyak Guru Pamekasan Belum Fasih Baca Al-Quran. (2016, September 15).

Koran Madura. https://www.koranmadura.com/2016/09/15/banyak-guru-paipamekasan-belum-fasih-baca-al-quran/

Budiman, A., \& Ariani, D. (2014). Aplikasi Interaktif Pengenalan Pahlawan Revolusi Indonesia Berbasis Multimedia. Jurnal Sisfotek Global, 4(2), 2-6.

Dawud Al-Aththar. (1994). Perspektif Baru Ilmu Al-Qur'an. Pustaka Hidayah.

DePorter, B. (2005). Quantum Teaching: Mempraktikkan Quantum Learning di Ruang-Ruang Kelas. Kaifa.

Faroqi, A., \& Maula, B. (2014). Aplikasi Multimedia Interaktif Pembelajaran Membaca, Menulis, Berhitung (Calistung). Jurnal Istek, VIII(2).

Guru Agama Islam di Singkawang Kurang Pandai Mengaji. (2014, October 10). Tribun Pontianak. http://pontianak.tribunnews.com/2014/10/10/guru-agamaislam-di-singkawang-kurang-pandai-mengaji/

Holilulloh, A., \& Youssef, B. (2020). The Learning Process Through Social Media For Children: "The Issues and Challenges of Children's Future." Scaffolding: Jurnal Pendidikan Islam Dan Multikulturalisma, 2(1), 58-67. https://doi.org/https://doi.org/10.37680/scaffolding.v2i1.261

Jahangir, S. F., \& Nawaz, N. (2014). Effects of memorizing Quran by heart (hifz) on later academic achievement. Journal of Muslim Mental Health, 8(2), 10381607. https://doi.org/10.3998/jmmh.10381607.0008.208

Khalid, muhammad rusdi. (2011). Mengkaji Ilmu-Ilmu Al-Quran. alauddin universiti press.

Macmillan, B. (2004). Permainan Kata dan Musik (Word and Music Games). 
Karisma Publishing Group.

Nawaz, N., \& Jahangir, P. D. S. F. (2015). Effects of Memorizing Quran by Heart

(Hifz) On Later Academic Achievement. Journal of Islamic Studies and Culture, 3(1), 58-64. https://doi.org/10.15640/jisc.v3n1a8

Novaliendry, D. (2013). Aplikasi Game Geografi Berbasis Multimedia Interaktif

(Studi Kasus Siswa Kelas IX SMPN 1 Rao). JURNAL TEKNOLOGI INFORMASI \& PENDIDIKAN, 6(2), 106-118.

Purnama, M. N. A. (2019). Implementasi Pendidikan Agama Islam yang Integratif

( Antara Guru, Orang Tua, dan Masyarakat ). Qalamuna: Jurnal Pendidikan, Sosial, Dan Budaya, 11(2), 1-15.

Sanaky, H. A. (2009). Media Pembelajaran. Safiria Insani Press.

Sanaky, H. A. (2011). Media Pembelajaran. Remaja Rosdakarya.

Shalikhah, N. D. (2016). Pemanfaatan Aplikasi Lectora Inspire sebagai Media Pembelajaran Interaktif. Cakrawala, XI(1), 101-115.

Shirvani, M., Heidari, M., Shahbazi, S., Sheikhi, R. A., Borujeni, M. B., \& Mancheri, H. (2015). Comparison of Intelligence test Results among Hafiz and Non-Hafiz of Holy Quran Students at Their Entrance to Schools. Int. J. Rev. Life. Sci. (CJK Welfare \& Pharmascope Foundation | International Journal of Review in Life Sciences, 5(8), 1105-1109.

Solihin, R. (2020). Akidah dan Akhlak dalam Perspektif Pembelajaran PAI di Madrasah Ibtidaiyah. Ibriez: Jurnal Kependidikan Dasar Islam Berbasis Sains, 5(1), 83-96. https://doi.org/https://doi.org/10.21154/ibriez.v5i5.92

Sumantri, M., \& Permana, J. (2001). Strategi belajar mengajar. In C. Maulana (Ed.), Bandung: CV Maulana.

WafaIndonesia. (2015). Panduan Pembelajaran Wafa: Metode Belajar Al-Quran Metode Otak Kanan. Tim Wafa. 